\title{
Erzurum İli Narman İlçesi Sığırcılık İşletmelerinde Çiftlik Yönetimi Ve Buzağı Yetiştirme Uygulamaları
}

\begin{tabular}{|c|c|}
\hline Araştırma / Research & $\begin{array}{c}\text { Abdulkerim DiLER }{ }^{I}, \text { Olcay GÜLER }{ }^{2 *}, \operatorname{Recep} A Y D I N^{3}, \\
\text { Mete YANAR }{ }^{3}, \text { Rudvan KOCYIGGIT }\end{array}$ \\
\hline 07.04 .2017 & ${ }^{1}$ Atatürk Üniversitesi, Erzurum Meslek Yüksekokulu, Bitkisel ve Hayvansal \\
\hline $\begin{array}{l}\text { Kabul Tarih / Accepted } \\
\text { 31.05.2017 }\end{array}$ & $\begin{array}{c}\text { Üretim Bölümü, Erzurum- Türkiye } \\
{ }^{2} \text { Atatürk Üniversitesi, Hinıs Meslek Yüksekokulu, Laborant ve Veteriner }\end{array}$ \\
\hline $\begin{array}{l}\text { DOI } \\
\text { 10.28955/alinterizbd.304466 }\end{array}$ & $\begin{array}{c}\text { Sağll̆ğı Bölümü, Erzurum- Türkiye } \\
{ }^{3} \text { Atatürk Üniversitesi, Ziraat Fakültesi, Zootekni Bölümü, Erzurum- Türkiye }\end{array}$ \\
\hline $\begin{array}{l}\text { ISSN 2564-7814 } \\
\text { e-ISSN 2587-2249 }\end{array}$ & *e-posta: olcay.guler@atauni.edu.tr \\
\hline
\end{tabular}

Öz: $\mathrm{Bu}$ araştırma, sığır yetiştiricilerinin çiftlik yönetimi ve buzağ yetiştirme uygulamalarını belirlemek amacıyla Erzurum İli Narman İlçesi'nde yapılmıştır. Bu amaçla Narman ilçe ve köylerinde 208 işletme sahibiyle yüz yüze anket çalıșması yapılarak veriler elde edilmiștir. Ankete katılan yetiştiricilerin sadece $\% 13,5^{\prime} \mathrm{i}$, düzenli olarak kayıt tuttuğunu ifade etmiş̧ir. İşletmelerin \%59'unun teknik bilgi desteği alma ihtiyacı hissettiklerini ve çoğunlukla (\%31) bu bilgiyi Veteriner Fakültesi vasıtasıyla edindikleri belirlenmiştir. İneklerin kızgınlığa gelme belirtisi olarak işletmelerin çoğunluğunun (\%43) genel belirtilerin hepsini esas aldığı ve yetiştiricilerin \%83'ünün doğum sonrası ilk kızgınlıkta tohumlama yaptıkları tespit edilmiştir. Yetiştiricilerin \%66'sının suni tohumlama yaptırırken \%97'si bu uygulamadan memnun kaldığını bildirmiştir. İşletmelerin \%47'sinde buzağılara ağız sütü verilmediği belirlenmiş, verilen işletmelerde ise buzağıların ağız sütünü annesini emerek (\%40) ya da biberonla (\%57) aldığı saptanmıştır. Ayrıca, yetiştiricilerin $\% 84$ ü üç günden daha az süreyle ağız sütü verdiklerini ifade etmişlerdir. Buzağılara normal süt verme süreleri ise çoğunlukla 4-5 (\%51) aydir.

Anahtar Kelimeler: Erzurum, Narman, süt sığırcıllı̆ı, çiftlik yönetimi, buzağı, besleme, sütten kesme

\section{Cattle Feeding Habits of Cattle Enterprises in Narman County of Erzurum Province}

\begin{abstract}
This study was carried out to determine cattle breeders' farm management and calf raising practices in Narman county of Erzurum province. For this purpose, some data were obtained by conducting a face to face survey study with 208 producers in Narman county. Just $13,5 \%$ of breeders who participated in the survey stated that they kept records of their animals regularly. $59 \%$ of the cattle breeders indicated that they were in the need of technical assistance about cattle rearing, and $31 \%$ of them who needed assisstance got this knowledge through College of Veterinary. In most of the enterprises (43\%), breeders based on all of the general signs of heat and cows in the $83 \%$ of the enterprises cows are inseminated in the first heat after birth. While $66 \%$ of the breeders used artificial insemination, $97 \%$ of breeders who used this method claimed that they were happy with this practice.It was determined that in $47 \%$ of the enterprises colostrum is not offered to new-born calves. In the enterprises that colostrum is offered to calves, they got the colostrum by sucking their dams $(40 \%)$ or by milk bottles $(57 \%)$. Furthermore, $84 \%$ of breeders stated that they fed their calves by colostrum less than 3 days. Milk feeding period for calves were usually 4-5 months (51\%).
\end{abstract}

Keywords: Erzurum, Narman, dairy cattle, farm management, calf, feeding, weaning

\section{GİRIS}

Tarımsal etkinliklerin bir kolu olan hayvancılık, Erzurum için önemli ekonomik kaynaklardan birisidir. Bölgemizdeki arazinin engebeli olması ve çayır-mera arazilerinin genişliği hayvancılığı önemli ekonomik etkinlik haline getirmiştir. Erzurum İli sığır varlığı 649.473 baştır. Bunların \%14,7'si kültür ırkı, \%77,7'si kültür melezi, \%7,6'sı yerli sığırlardan oluşmaktadır (Anonim, 2017). Sağılan inek sayısı ise 251.673 baș olup üretilen süt miktarı 729.637 tondur. Narman ilçesinin sağmal inek sayısı ve üretilen süt miktarındaki payı ise Erzurum İl'inin sırasıly \%1,6 ve \%4,9'unu oluşturmaktadır. 
TUİK verilerine göre genelde Türkiye'de özelde ise bölgemizde hayvan sayısının fazla olmasına karşılık hayvan başına düşen süt üretiminin düşük düzeyde olduğu görülmektedir. Bunun en önemli sebeplerinden bir tanesi işletmelerin çiftlik yönetimi ve organizasyonu hakkında yeterli bilgi ve beceriye sahip olmamaları gelmektedir. İstenilen üretim düzeyine ulaşmak ancak işletme unsurlarının politik, ekonomik ve fiziksel çevre şartlarında modern yetiştiricilik amaçları ve tercihleri doğrultusunda işletme kaynaklarının maksimum düzeyde yönetilmesi ve yönlendirilmesi ile gerçekleşebilir.

$\mathrm{Bu}$ çalışma Narman İlçesinde mevcut sığırcılık işletmelerinin çiftlik yönetimi ve buzağı yetiştirme uygulamaları açısından değerlendirilerek sorunları ve çözüm önerilerini ortaya koymak amacıyla yapılmıştır.

\section{MATERYAL VE YÖNTEM}

Araştırma materyalini Erzurum ili Narman İlçesi ve köylerinde bulunan 2033 adet sığırcılık işletmesinden tesadüfen seçilmiş 208 sığırcılık işletmesi ile yapılan anketler oluşturmuştur. Anket çalışmalarında örnek hacminin en az \%3’ü (Yamane, 2006) veya \%10’unun (Cochran, 1977) alınmasının yeterli olacağı bildirilmiştir. Narman ilçesinde işletmelerin \%10,23'ünü oluşturan 208 sığırcılık işletme sahibiyle yüz yüze görüşülerek anket çalışması yapılmıştır.

Elde edilen veriler işletmenin yapısal durumunu etkileyen yetiştiricilerin eğitim [6 grup (okuryazar değil, ilkokul terk, ilkokul mezunu, orta okul mezunu, lise mezunu ve üniversite mezunu)] ve deneyim durumu [5 grup (0-10, 11-20, 21-30, 31-45 ve daha fazla yıl)] dikkate alınarak SPSS (20.0) paket programında analiz edilmiştir. Araştırmada elde edilen sonuçlara uygun şekiller oluşturularak gerekli yorumlar yapılmıştır. Değişkenler arasındaki ilişkilerin belirlenmesinde ki-kare bağımsızlık testi uygulanmıştır (Yıldız ve Bircan 2006).

\section{ARAŞTIRMA BULGULARI VE TARTIŞMA}

\section{Çiftlik Yönetimi}

Erzurum İli Narman İlçesi'nde sığırcılık işletmelerinin \%13,5'inde hayvanlara ait bireysel kayıtların tutulduğu saptanmıştır (Şekil 1). Yetiştiricilerin eğitim durumu ve deneyim sürelerinin kayıt tutma alışkanlığını etkilemediği tespit edilmiştir. Yetiştiricilerin genelde kayıt tutma eğiliminde olmadığı görülmüştür. Benzer şekilde Çoban ve ark., (2013) Erzurum İl'inde kayıt tutma oranını \%13,3 olarak bildirmişlerdir.

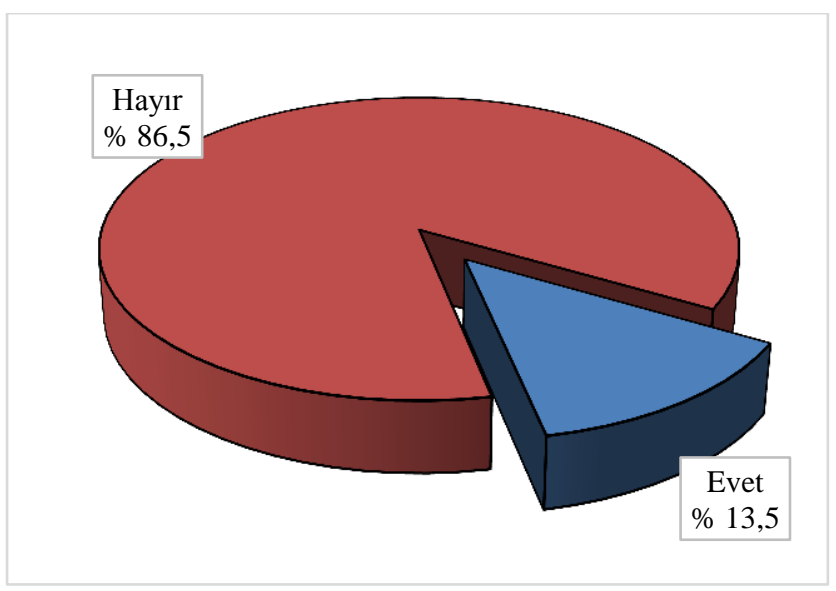

Şekil 1. İşletmelerde kayıt tutma oranı (\%)

Erzurum İli Hınıs ilçesinde Koçyiğit ve ark., (2015) yapmış oldukları çalışmada kayıt tutma oranını \%26 olarak tespit etmişlerdir. İşletmelerin hayvan sayısı ve işletmecilerin eğitim düzeyinin kayıt tutma alışkanlığını önemli derecede $(\mathrm{P}<0.01)$ etkilediğini ifade etmişlerdir. Yapılan diğer çalışmalarda ise kayıt tutma oranlarını Özyürek ve ark., (2014) \%48, Kaygısız ve ark., (2008) \%37 ve Ildız (1999) $\% 24,4$ olarak bildirmişlerdir.

İşletmelerde düzenli bir şekilde kayıt tutmak sadece yetiştiriciye değil, oluşturacağı katma değer ile ülke ekonomisine de katkı sağlayacaktır. Özellikle süt sığırcılığı işletmelerinde pedigri, döl verimi, süt verimi, somatik hücre sayısı, vücut kondisyon skoru ve işletme muhasebesi gibi kayıtların tutulması 
verimliliğin, karlılığın ve işletmenin geleceği konusunda doğru ve isabetli karar verme açısından çok önemlidir. Bu konuda yetiştiricilerin daha titiz davranması gerekmektedir.

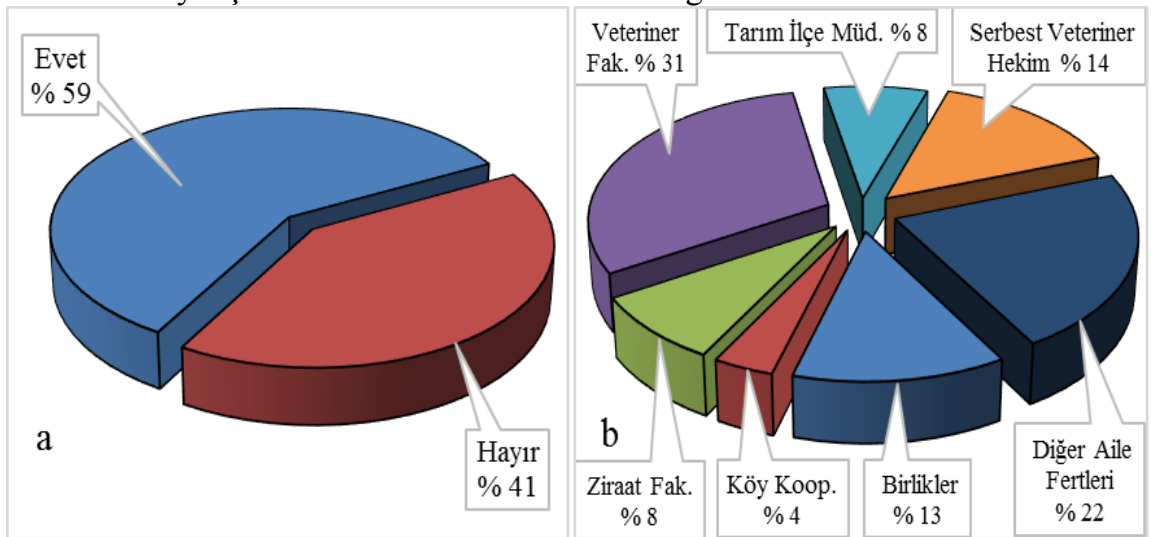

Şekil 2. Teknik Bilgi desteği alma durumu (a) ve kaynakların dağılımı (b) (\%)

Narman İlçesi'ndeki sığır yetiştiricilerinin \%59'unun teknik bilgi desteği alma gereksinimi duydukları, ancak \%41'lik bir kesimin hayvancıllkla ilgili teknik bilgilerini yenileme ve geliştirme ihtiyacı duymadıkları belirlenmiştir (Şekil 2a). Bilgi desteği alan yetiştiriciler ise çoğunlukla (\%31) Veteriner Fakültesini tercih etmişlerdir (Şekil 2a). Benzer şekilde Ünalan ve ark., (2013) Niğde İl'inde bilgi desteği alanların oranını \%66 olarak bildirirken, Goonewardenet ve ark., (1995), Kanada da, en çok faydalanılan teknik bilgi kaynağ 1 olarak $\% 81,1$ oranıyla veteriner hekimlerin olduğunu bildirmişlerdir. Diğger taraftan Koçyiğit ve ark., (2015) yetiştiricilerinin \%83'ünün teknik bilgi desteği alma gereksinimi duymadıklarını, teknik bilgi desteği alanların ise $\% 58$ oranında birlikleri tercih ettiklerini belirtmişlerdir.

Araştırmaya konu teşkil eden Narman İlçesi'nde, ineklerin kızgınlığa gelme belirtisi olarak işletmecilerin \%43'ü genel belirtilerin hepsini esas alırken, \%29'u başka hayvanlara atlamasını, \%14'ü böğ̈̈rmesini ve \%14'ü çara akıntısının gelmesini esas aldıkları belirlenmiştir (Şekil 3a). Kahramanmaraş Ill'inde Kaygısız ve ark., (2008) yoğun bir şekilde böğürme ve sıçrama davranışlarının, Şeker ve ark., (2012) Muş İlinde atlama ve sıçrama hareketlerinin(\%45,7), Tugay ve Bakır (2008) Giresun yöresinde çara akıntısının (\%53,9), Koçyiğit ve ark., (2015) ise Hınıs ilçesinde hayvanın böğürmesinin (\%63) kızgınlık tespitinde esas alındığını bildirmişlerdir.

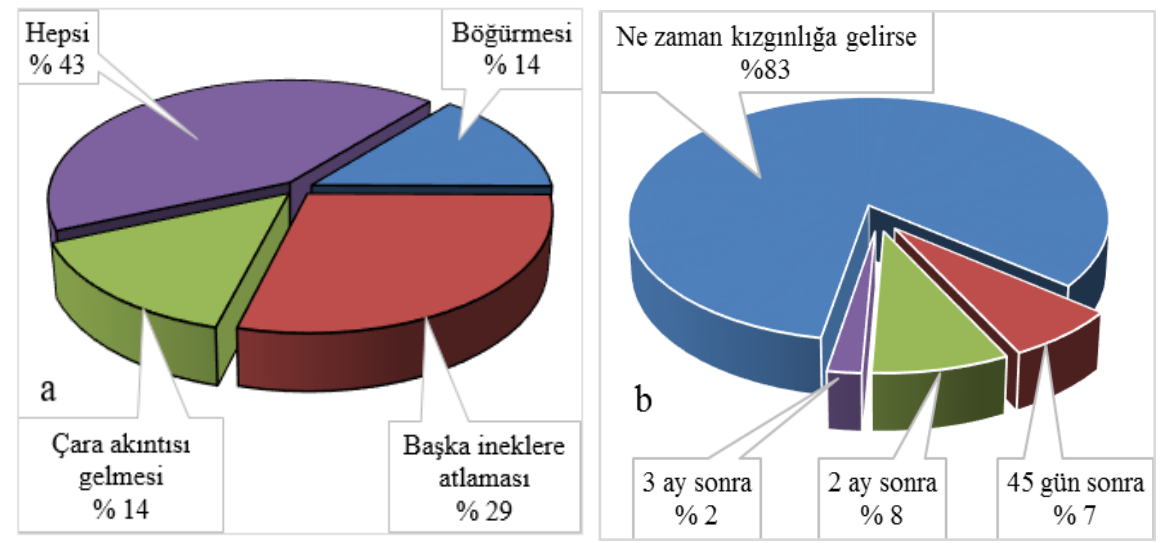

Şekil 3. Kızgınlığın tespitinde dikkate alınan unsurlar (a) ve tohumlama zamanı (b) (\%)

Narman İlçesinde yetiştiricilerin \%83'ü doğum sonrası ilk kızgınlıkta, \%8'i doğumu takiben 2 ay sonra, \%7'si doğum sonrası 45. günden sonraki ilk kızgınlıkta, \%2'si ise doğumdan 3 ay sonraki ilk kızgınlıkta tohumlama yaptırdıkları tespit edilmiştir (Şekil 3b). Normal koşullar altında doğum sonrası 60. günü takip eden ilk kızgınlıkta tohumlama yapılması önerilmektedir. Doğum sonrası ilk kızğınlık görülmesi ise 30. günden sonra başlamaktadır (Özhan ve ark. 2012). İşletmelerin yaklaşık \%90’1 önerilen süreden daha erken dönemde doğum sonrası tohumlama yaptırdığı görülmektedir. Bu durum hem döl veriminde hemde süt veriminde bir dezavantaj oluşturabilir. Söz konusu işletmelerde 
optimum döl verim performansı için doğum sonrası kızgınlık için ineğe zaman tanınmalı ve ineğin ${ }^{\circ}$ doğum öncesi ve sonrası gereği kadar besin maddesi alması sağlanmalıdır. Yapılan çalışmalarda işletmelerin doğum sonrası ideal tohumlama zamanı uygulaması oranlarını Tugay ve Bakır (2008) \%52,8, Kaygısız ve ark., (2008) \%46, Şeker ve ark., (2012) \%25 ve Koçyiğit ve ark., (2015) ise \%10 olarak bildirmiştir.

Yapılan çalışmalarda, Kahramanmaraş (Kaygısız ve ark. 2008), Muş (Şeker ve ark. 2012) ve Giresun'daki (Tugay ve Bakır, 2008) süt sığırcılığ zamanı uygulama oranlarının (sırasıyla, $\% 46, \% 25$ ve $\% 52,8$ ) bu çalışmada elde edilen sonuçtan daha yüksek bulunmuştur.

Yetiştiricilerin \%66'sının suni tohumlama yaptırdığı ve suni tohumlama uygulaması yapanların tamamına yakını (\%97) memnun kaldığını ifade etmiștir. İșletmelerin \%52'sinde işletmeye ait bir boğanın olduğu, suni tohumlama yaptırmayan yetiştiricilerin kendi boğalarını kullandığı, bazı işletmelerin ise tabii ve suni tohumlamayı bir arada yaptıkları tespit edilmiştir. İşletmede kullanılan boğanın 1-10 inekte kullanım oranı \%76, 11-20 inekte \%21, 21 ve daha fazla inekte kullanım oranı ise $\% 3$ olarak belirlenmiștir. Suni tohumlama uygulaması ve boğa kullanımı üzerine eğitim durumu ve deneyim sürelerinin herhangi bir etkisi olmamıştır. Suni tohumlama için tespit edilen değer, Koyubenbe (2005)'nin (\%53) ve Soyak (2006)'ın (\%68) bildirdiği değerlerle benzer ve Kaygısız ve ark., (2008)'nın (\%38) ve Demir (2011)'in (\%11,2) bildirdiği değerlerden yüksek bulunmuştur.

Narman İlçesinde yetiştiricilerin \%78'inin inekleri sütten kesilince kuruya çıkardıkları belirlenmiştir (Şekil 4). İneklerin kuruya çıkarılmasında eğitim durumu ve deneyim sürelerinin herhangi bir etkisinin olmadığı tespit edilmiştir. Sağmal gebe inekler en geç doğuma iki ay kala kuruya çıkarma işlemi yapılmalıdır (Özhan ve ark. 2012). Yetiştiricilerin inekleri kuruya çıkarma uygulamalarında hatalar yaptıkları ve bu konuda bilgi eksikliği bulunduğu söylenebilir.

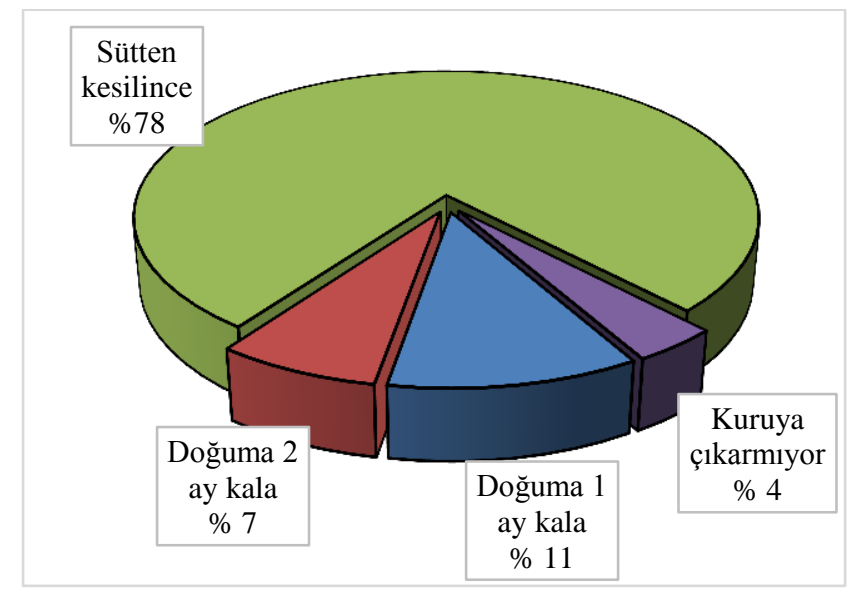

Şekil 4. İneklerin kuruya ayrılma dönemleri (\%)

Yurdumuzda yapılan diğer çalışmalarda, Şeker ve ark., (2012) yetiştiricilerin \%46's1 süt verimi kesilince, \%12'si doğuma kadar, \%38,7'si doğuma iki ay kala, Tugay ve Bakır (2008) \%82,8'i doğuma iki ay kala, \%17,2'si ise sütten kesilene kadar sağıldığını, Koçyiğit ve ark., (2015) ise işletmecilerin \%65'inin ineklerin süt verimi kesilene kadar, \%13'ünün doğuma bir ay kala, \%10'unun doğuma iki ay kala inekleri kuruya çıkardığını ve \%11'inin ise inekleri kuruya çıkarmadığını rapor etmişlerdir.

\section{Buzağı Yetiştirme Uygulamaları}

Söz konusu işletmelerin \%47'sinin buzağılara ağız sütü (kolostrum) vermediği tespit edilmiştir (Şekil 5a). Yetiştiricilerin ağız sütünü verme süresi ise çoğunlukla bir gün (\%42) ve iki gün (\%42) olarak belirlenmiştir (Şekil 5b). 


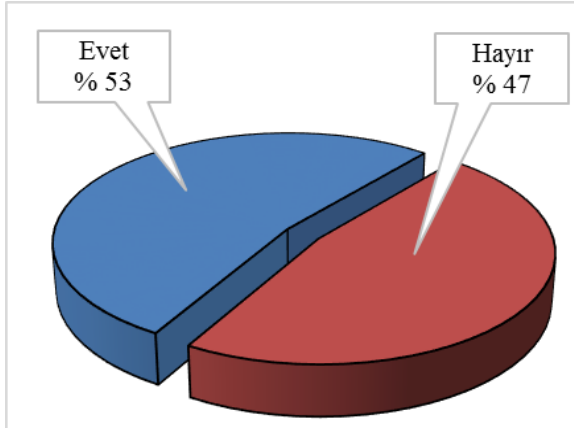

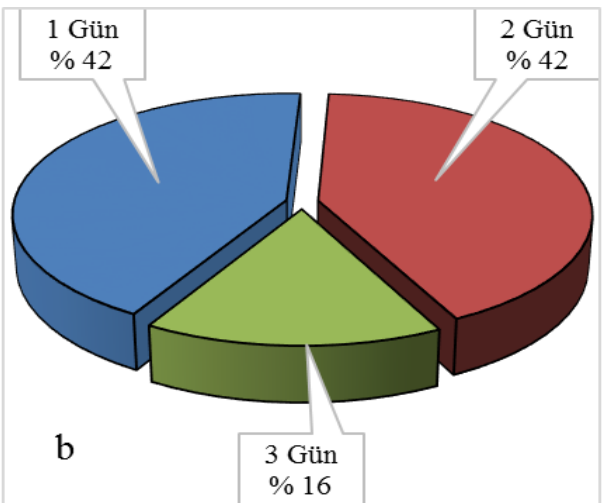

Şekil 5. Buzağılara ağız sütü verilme durumu (a) ve verilme süreleri (b) (\%)

Buzağıların sağlığı ve yaşama gücü üzerinde önemli bir etkisi olan ağız sütünün mutlaka verilmesi ve bu uygulamanın en az üç gün süreyle yapılması gerekmektedir. İlçede yetiştiricilerin \%47'sinin buzağılara ağı sütü vermediği ve ağ1z sütü verenlerin ise çoğunluğunun (\%84) üç günden daha az süreyle verdiği göz önüne alındığında yetiştiricilerin uygulamalarındaki hataları ve bu konudaki eksiklerinin giderilmesi gerekmektedir.

Erzurum ili Hınıs ilçesinde yapılan bir çalışmada Koçyiğit ve ark., (2015) buzağılara ağız sütü veren işletmelerin oranını $\% 75$, verilme sürelerini ise $\% 11^{\prime}$ i bir gün, $\% 68$ 'i iki gün, $\% 21$ 'i üç gün olarak ifade etmişlerdir.

Araştırma konusu işletmelerde ağız sütü veren yetiştiricilerin \%40’1 annesini emzirerek, \%57'si biberonla, geri kalan kısmın ise kova ile ağız sütü verdikleri tespit edilmiştir. Koçyiğit ve ark., (2015) $\% 82$ oranında annesini emerek, \%10 oranında biberonla, \%7 oranında kovayla verildiğini bildirmiştir. Hannien ve ark., (2007) işletmelerin \%51,3'ünün biberon ile, \%36,5'inin kova ile ağız sütü verdiklerini, Heinrichs ve ark., (1987) \%57,8'inin annesini emerek, geri kalan kısmın ise emzikli kovalar ile verildiğini, Vasseur ve ark., (2010) ise işletmelerin \%92'sinde sütün kovalarda, \%17,7 inde ise emzikli biberonlarda buzağılara verdiklerini rapor etmişlerdir.

Ankete konu olan işletmelerde yeni doğan buzağıların analarıyla birlikte bir hafta kalanların oranı $\% 61$ iken, \%26 oranında üç gün, \%13 oranında bir haftadan daha fazla süreyle anası ile birlikte kaldıkları belirlenmiştir (Şekil 6a). Buzağılara normal süt verme süreleri ise çoğunlukla 4-5 ay (\%51) olarak tespit edilmiştir (Şekil 6b). Genellikle yörede normal süt buzağılara sağım öncesi anadan emzirilerek verilme şeklinde gerçekleşmektedir. Bu durumunda ana yavrusunu görmeden sütünü indirmediğinden yetiştirici mecburen buzağısını anasının yanına bırakmak zorunda kalmaktadır. Bu alışkanlık buzağıların sütten kesim süresini uzatmaktadır.

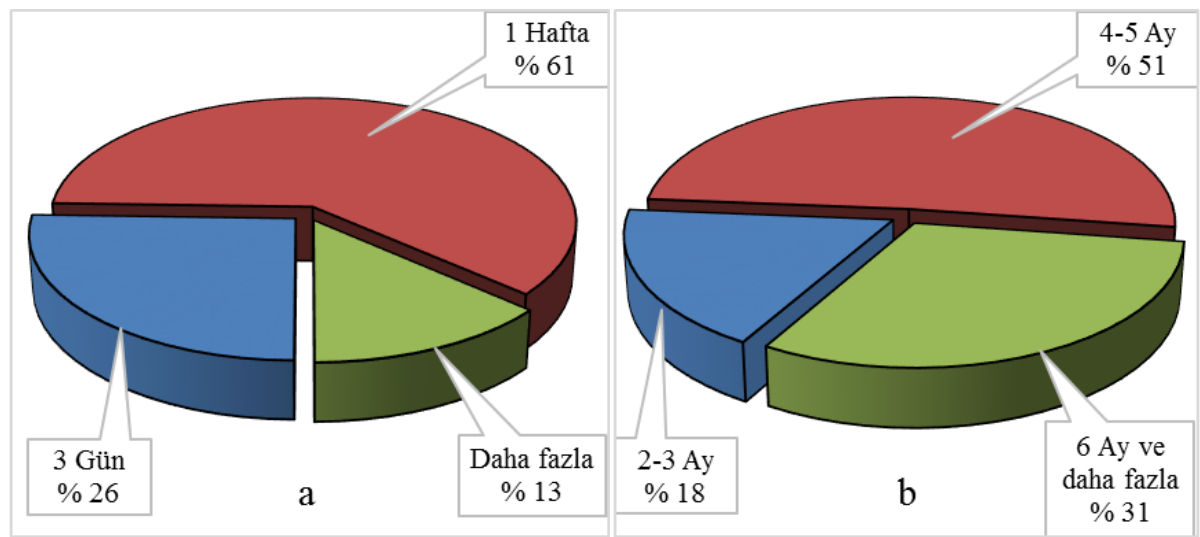

Şekil 6. Buzağıların analarıyla birlikte kalma (a) ve normal süt verme süreleri (\%)

Yapılan diğer çalışmalarda Vasseur ve ark., (2010) Kanada'daki işletmelerin çoğunlukla $(\% 73,2)$ doğum sonrası ilk 12 saatlik dönemde, geri kalan kısmın $(\% 32,5)$ ise doğumdan hemen 2 saat sonra analarından ayrıldığını bildirilmiştir. Koçyiğit ve ark., (2015) ise yeni doğan buzağıların \%57'sinin 
analarıyla birlikte bir haftadan daha fazla, \%24'ünün bir hafta ve \%19'unun ise üç gün süreyle birlikte kaldıklarını ifade etmişlerdir.

\section{SONUÇ VE ÖNERILER}

Bu çalışmada Erzurum ili Narman İlçesi’ndeki sığırcılık işletmelerinin çiftlik yönetimi ve buzağı yetiştirme uygulamaları belirlenmeye çalışılmıştır. Narman İlçesi'nde sığırcılık işletmelerinin \% 13,5'inde hayvanlara ait bireysel kayıtların tutulduğu, \% 59'unun teknik bilgi desteği alma gereksinimi duydukları belirlenmiştir. İşletmelerin geleceği konusunda isabetli kararlar verebilmesi için kayıtların düzenli bir şekilde tutulması ve bilgilerin sürekli güncellenmesi gerekmektedir.

Süt sığırcıllğı işletmelerinde üretim birimleri ineklerdir ve yılda bir buzağı almak esastır. Bundan dolayı ineklere doğru bakım ve beslemenin yapılaması gerekir. İşletmelerde kızgınlık dönemi takibi, tohumlama, gebelik süreci ve kuruya çıkarma gibi uygulamaların titizlikle yapılması gerekmektedir. $\mathrm{Bu}$ konularda yetiştiricilerin uygulamadaki hataları ve eksiklikleri giderilmelidir.

Kolostrum yeni doğmuş buzağıların hastalıklara karşı direncin sağlanmasında yaşamsal önem taşımaktadır. Ancak işletmelerin \% 47'sinin buzağılara ağız sütü vermediği görülmektedir. Diğer taraftan normal sütün anadan emzirilmesi; ineğin buzağısına bağımlı hale gelmesine ve buzağıların sütten kesim sürelerinin uzamasına dolayısıyla işletmede sütten elde edilen gelirin azalmasına sebep olmaktadir.

Sonuç olarak işletmeciler düzenli olarak üretim oranlarını ve üretkenlik performans seviyelerini karşllaştırmalı, üretim süreçlerini izlemeli ve gerektiğinde gerekli değişimleri yapmalı ve kayıt tutma alışkanlığı edinmelidir. Bu konularda ilgili paydaşların üzerine düşen görevleri ivedilikle yerine getirmesi beklenmektedir.

\section{KAYNAKLAR}

Anonim, 2017. Hayvansal Üretim İstatistikleri. http://tuik.gov.tr/ [Erişim tarihi:21.03.2017]

Cochran, W.G., 1977. Sampling Techniques. 3rd Edition. John Wiley and Sons. New York.

Çoban, O., Laçin, E., Sabuncuoğlu, N and Genc, M., 2013. Production and health parameters in cattle herds: a survey from eastern Turkey. The Journal of Animal and Plant Sciences, 23 (6), 1572-1577.

Demir, P., 2011. Kars İlindeki süt üreticilerinin bazı teknik bilgi düzeylerinin araştırılması. Atatürk Üniversitesi Veteriner Bilimleri Dergisi, 6 (1), 47-54.

Goonewardenet, L. A., Spicert, H.M., McNeil, A.O., and Slack, W. L., 1995. A survey of production characteristics, ownership and extension needs of the Alberta dairy industry. Can. J. Anim. Sci. 75 (2), 181-184.

Hannien L, Hepola H, Raussi S, Saloniemi H, 2007. Effect of colostrum feeding method and presence of dam on the sleep, rest and sucking behavior of newborn calves. Appl. Anim. Behav. Sci., 112:213-222.

Heinrichs, A. J., Kiernan, N. E., Graves, R. E., And Hutchinson, L. J., 1987. Survey of calf and heifer management practices in Pennsylvania dairy herds. J Dairy Sci 70 (4), 896-904.

Ildız, F., 1999. Tokat İli merkez ilçesinde ithal sığır yetiștiren tarım işletmelerinin yapısı. Ankara Üniversitesi Fen Bilimleri Enstitüsü Zootekni Anabilim Dalı.(Yüksek Lisans Tezi, Basılmamış). Ankara.

Kaygısız, A., Tümer, R., Orhan, H., Vanlı, Y., 2008. Kahramanmaraş bölgesi süt sığırı işletmelerinin yapısal özellikleri: 1. yetiştirme uygulamaları. Süleyman Demirel Üniversitesi Ziraat Fakültesi Dergisi 3 (2), 23-31.

Koçyiğit, R., Diler, A., Yanar, M., Güler, O., Aydın, R., Avcı, M., 2015. Erzurum İli Hınıs İlçesi sığırcılık işletmelerinin yapısal durumu: Çiftlik yönetimi ve buzağı yetiştirme uygulamaları. Iğdır Üni. Fen Bilimleri Enst. Der. 5 (4), 85-97.

Koyubenbe, N., 2005. İzmir ili ödemiş ilçesinde süt sığırcılığının geliştirilmesi olanakları üzerine bir araştırma. Hayvansal Üretim, 46: 8-13.

Özhan, M., Tüzemen, N., Yanar, M., 2012. Büyükbaş Hayvan Yetiştirme. Atatürk Üniv. Ziraat Fak. Ders Notu Yay. No:134. Erzurum.

Özyürek, S., Kocyigit, R., Tuzemen, N., 2014. Erzincan İlinde süt sığırcılığı yapan işletmelerin yapısal özellikleri: Çayırlı İlçesi örneği. Tekirdağ Ziraat Fakültesi Dergisi. 11 (2), 19-26.

Soyak, A., 2006. Tekirdağ ili süt sığırcılığı işletmelerinin yapısal özellikleri ve bu işletmelerin siyah alaca süt sığırı popülasyonunun çeşitli morfolojik özellikleri üzerine bir araştırma. Trakya Ünv. Fen Bil. Ens., Yüksek Lisans Tezi, Tekirdağ.

SPSS 2012. Analysis Without Anguish: Version 20 for Windows. John Wiley and Sons Australia

Şeker, İ., Tasalı, H., Güler, H.2012. Muş İlinde sığır yetiştiriciliği yapılan işletmelerin yapısal özellikleri. F.Ü. Sağ. Bil. Vet. Derg., 26 (1), 09-16.

Tugay, A., Bakır, G., 2008. Giresun Yöresindeki Süt Sığırcılığı İşletmelerinin Yapısal Özellikleri. Atatürk Üniversitesi Ziraat Fakültesi Dergisi 40(1), 37-47. 
Ünalan, A., Serbester, U., Çınar, M., Ceyhan, A., Akyol, E., Şekeroğlu, A., Erdem, T., Yılmaz, S., 2013. Niğde İli süt sığırcılığı işletmelerinin mevcut durumu, başlıca sorunları ve çözüm önerileri. Türk Tarım - Gida Bilim ve Teknoloji Dergisi, 1 (2), 67-72.

Vasseur, E., Borderas, F., Cue, R. I., Lefebvre, D., Pellerin , D., Rushen, J., Wade, K. M., Passillé, A. M., 2010. A survey of dairy calf management practices in Canada that affect animal welfare. Journal of Dairy Science. 93 (3), 1307-1315.

Yamane, T., 2006. Temel Örnekleme Yöntemleri. Çev. Esin, A., Bakır, M.A., Aydın, C, Güzbüzsel, E. Literatür Yayınlar1: 53, İstanbul.

Yıldız, N. ve Bircan, H., 2006. Uygulamalı İstatistik. Nobel Yayın Dağıtım, Ankara. 